\title{
Utilização de complexo enzimático em dietas à base de sorgo-soja para frangos de corte
}

\author{
Maria do Socorro Vieira dos Santos ${ }^{1}$, Gastão Barreto Espíndola², Maria de Fátima Freire \\ Fuentes $^{2}$, Ednardo Rodrigues Freitas ${ }^{2}$, Luiz Euquério de Carvalho
}

\author{
${ }^{1}$ Bolsista DCR/CNPq/UFRR, CEP 69309-210, Boa Vista-RR. \\ 2 Departamento de Zootecnia - UFC, Caixa Postal 12168, CEP 60356-000, Fortaleza-CE.
}

\begin{abstract}
RESUMO - Este experimento foi conduzido com os objetivos de avaliar o desempenho e o peso dos órgãos do trato gastrointestinal e analisar economicamente a produção de frangos de corte submetidos a dietas à base de sorgo e soja, suplementadas ou não com complexo multienzimático (xilanase, amilase, protease), nas fases inicial (experimento I) e final (experimento II) de crescimento. O delineamento estatístico foi em blocos ao acaso, em esquema fatorial $3 \times 2$ (três níveis de sorgo $=0,50$ e $100 \%$ e dois níveis de enzima $=0$ e $0,1 \%$ ), em que a unidade experimental foi constituída de um boxe com 17 aves e oito repetições por tratamento. No experimento I ( 1 a 21 dias), não houve efeito significativo do nível de substituição do milho pelo sorgo sobre o consumo de ração, o ganho de peso e a conversão alimentar. Entretanto, o acréscimo no nível de sorgo ocasionou redução no peso relativo da moela e a suplementação enzimática aumentou o peso relativo do jejuno e íleo. No experimento II (22 a 42 dias), não houve efeito significativo do nível de substituição do milho pelo sorgo sobre o consumo de ração, o ganho de peso, a conversão alimentar e os pesos relativos do duodeno, jejuno, íleo e ceco. A suplementação enzimática reduziu significativamente o rendimento de carcaça e aumentou o peso do proventrículo, da moela e do pâncreas. A análise econômica revelou que o sorgo pode substituir $50 \%$ do milho em rações para frangos de corte nas fases inicial e final do crescimento.
\end{abstract}

Palavras-chave: desempenho, enzimas, sorgo, trato gastrointestinal

\section{Effects of feeding sorghum-soya of enzymatic supplementation on broiler chickens based diet}

\begin{abstract}
The trial was conducted to evaluate the performance and morphologic changes of gastrointestinal tract and economic analysis for broilers fed sorghum-soybean meal-based diets, supplemented or not with multienzymatic complex (xilanase, amylase, protease), in the starting (experiment I) and finishing (experiment II) phases. The experiment was analyzed as a randomized block design with a $3 \times 2$ factorial arrangement [three sorghum levels (0, 50, and 100\%) x enzyme level $(0$ and $100 \%)$ ]. The experimental unit was a box with 17 birds and eight replicates per treatment. In the experiment I ( 1 to 21 days), the sorghum-based diets did not affect feed intake, weight gain, and feed conversion. However, the increase of level sorghum decreased gizzard weight and of enzyme increased jejunum and ileum weights. In the experiment II (22 to 42 days), the sorghum-based diets also did not affect broilers feed intake, weight gain, feed:gain ratio, and relative weights of duodenum, jejunum, ileum and caecum. Increasing enzyme levels decreased significantly carcass yield and increased weights pf proventriculus, gizzard and pancreas. Based on the economic analysis, it is suggested the corn replacement with sorghum of $50 \%$ for starting and finishing broilers.
\end{abstract}

Key Words: enzymes, gastrointestinal tract, performance, sorghum

\section{Introdução}

O sorgo é cultivado extensivamente em todo o mundo, especialmente nas zonas áridas e semi-áridas. No entanto, sua utilização na alimentação de aves é limitada por fatores antinutricionais, como o tanino, que provocam efeito negativo sobre a digestão em nível intestinal, ocasionando redução na energia metabolizável e na digestibilidade dos aminoácidos (Gualtieri \& Rapaccini, 1990).
Os monogástricos não possuem a capacidade enzimática para digerir pentosanas, $\beta$-glucanos ou pectinas. A suplementação de enzimas de origem exógena à dieta visa melhorar a utilização de matérias-primas e permitir o uso de fontes alternativas (Bedford, 1996).

Os objetivos neste trabalho foram avaliar o desempenho zootécnico e o peso dos órgãos do trato gastrointestinal e analisar economicamente a produção de frangos de corte submetidos a dietas à base de sorgo-soja, tratadas ou não com complexos enzimáticos. 


\section{Material e Métodos}

Foram utilizados 816 pintos machos de um dia, da linhagem HI-Y, distribuídos em um delineamento experimental de blocos ao acaso, em esquema fatorial $3 \times 2$ (três níveis de sorgo $\mathrm{x}$ dois níveis de enzima), em que a unidade experimental constituiu-se de um boxe com 17 aves e oito repetições por tratamento. O programa estatístico utilizado foi o pacote estatístico SAS (1996).

No delineamento experimental do rendimento de carcaça e do peso dos órgãos digestivos, retirou-se aleatoriamente uma ave em cada boxe (oito aves/tratamento), que foram pesadas, para comparação das médias pelo teste Tukey.

Os tratamentos constaram de seis dietas do tipo inicial ( 1 a 21 dias - experimento I) e seis do tipo final (22 a 42 dias - experimento II), diferenciadas quanto ao nível de sorgo em substituição ao milho, com e sem complexo enzimático. O complexo multienzimático (Avizyme 1500, Finnfeeds International), desenvolvido para aumentar o valor nutritivo de dietas (para aves) à base de milho-soja ou sorgo-soja contendo uma dose otimizada de níveis de xilanase, amilase e protease (300, 400 e $4.000 \mathrm{UI} / \mathrm{kg}$, respectivamente), foi misturado à ração na proporção de $1 \mathrm{~kg} /$ tonelada de ração, de acordo com as recomendações do fabricante.
A xilanase do Trichoderma longibrachiatum foi desenvolvida para que sua ação principal ocorresse ao longo do trato gastrointestinal, reduzindo a viscosidade e degradando as paredes celulares dos cereais. A amilase do Bacillus subtilis atua na região superior do trato gastrointestinal do animal, corrigindo a digestão incompleta do amido do endosperma. A protease subtilisina degrada as proteínas da soja, especificamente as de armazenamento (conglicina e beta-conglicina) e os fatores anti-nutricionais da soja, inibidores de tripsina, lectinas e proteínas antigênicas (Soto-Salanova et al., 1997).

As dietas, isocalóricas e isoprotéicas, foram formuladas com níveis de energia de $3.100 \mathrm{kcal} \mathrm{EM/kg}$ (dieta inicial) e $3.200 \mathrm{kcal} \mathrm{EM} / \mathrm{kg}$ (dieta final) e níveis de proteína de $22 \%$ para a dieta inical (experimento I) e $20 \%$ para a dieta final (experimento II), de acordo com as recomendações do NRC (1994). Na fase pré-experimental do experimento II (1-21 dias), o lote recebeu uma dieta única, com $0 \%$ de sorgo sem suplementação enzimática, com $3.100 \mathrm{kcal} \mathrm{EM} / \mathrm{kg}$ e $22 \%$ PB

Os tratamentos foram os seguintes: T1 - $0 \%$ de sorgo; T2 - $0 \%$ sorgo $+0,1 \%$ enzima; $\mathrm{T} 3-50 \%$ sorgo; $\mathrm{T} 4-50 \%$ sorgo $+0,1 \%$ enzima; T $5-100 \%$ sorgo; $\mathrm{T} 6-100 \%$ sorgo $+0,1 \%$ enzima (Tabela 1 e 2 ).

Tabela 1 - Composições percentual e calculada das dietas utilizadas no experimento I (fase inicial)

Table 1 - Ingredient and calculated compositions of the diets - experiment I (starting)

\begin{tabular}{|c|c|c|c|c|c|c|}
\hline \multirow[t]{2}{*}{ Ingrediente (Ingredient) } & \multicolumn{6}{|c|}{ Dieta (Diet) } \\
\hline & T 1 & T 2 & T 3 & T 4 & T 5 & T 6 \\
\hline Milho (Corn) & 54,740 & 54,530 & 26,733 & 26,523 & - & - \\
\hline Farelo de soja (Soybean meal) & 37,455 & 37,495 & 37,545 & 37,585 & 35,227 & 34,879 \\
\hline Óleo de soja (Soybean oil) & 3,703 & 3,773 & 4,227 & 4,297 & 4,230 & 4,216 \\
\hline Sorgo granífero (Sorghum) & - & - & 27,370 & 27,370 & 54,740 & 54,740 \\
\hline Glutenose $60 \%$ (Gluten) & - & - & - & - & 1,646 & 1,900 \\
\hline Fosfato bicálcico (Dicalcium phosphate) & 1,777 & 1,778 & 1,779 & 1,780 & 1,786 & 1,788 \\
\hline Calcário calcítico (Limestone) & 1,159 & 1,159 & 1,165 & 1,165 & 1,182 & 1,184 \\
\hline Sal (Salt) & 0,478 & 0,478 & 0,478 & 0,478 & 0,478 & 0,478 \\
\hline Premix mineral ${ }^{1}$ (Mineral premix) & 0,100 & 0,100 & 0,100 & 0,100 & 0,100 & 0,100 \\
\hline Premix vitamínico ${ }^{2}$ (Vitamin premix) & 0,300 & 0,300 & 0,300 & 0,300 & 0,300 & 0,300 \\
\hline DL-metionina (DL-methionine) & 0,288 & 0,288 & 0,303 & 0,303 & 0,297 & 0,294 \\
\hline L-lisina (L-Lysine) & - & - & - & - & 0,013 & 0,021 \\
\hline Avizyme $1500^{\circledR 3}$ & - & 0,100 & - & 0,100 & - & 0,100 \\
\hline \multicolumn{7}{|l|}{ Valor calculado (Calculated value) } \\
\hline $\mathrm{EM}, \mathrm{kcal} / \mathrm{kg}(M E)$ & 3.100 & 3.100 & 3.100 & 3.100 & 3.100 & 3.100 \\
\hline Proteína bruta (\%) (Crude protein) & 22,00 & 22,00 & 22,00 & 22,00 & 22,00 & 22,00 \\
\hline Fibra bruta (\%) (Crude fiber) & 3,49 & 3,49 & 3,29 & 3,29 & 3,00 & 2,98 \\
\hline Cálcio (\%) (Calcium) & 0,97 & 0,97 & 0,97 & 0,97 & 0,97 & 0,97 \\
\hline Fósforo disponível (\%) (Available P) & 0,44 & 0,44 & 0,44 & 0,44 & 0,44 & 0,44 \\
\hline Metionina (\%) (Methionine) & 0,54 & 0,54 & 0,54 & 0,54 & 0,55 & 0,55 \\
\hline Metionina + Cistina $(\%)($ Met + Cys $)$ & 0,87 & 0,87 & 0,87 & 0,87 & 0,87 & 0,87 \\
\hline Lisina $(\%)($ Lys $)$ & 1,12 & 1,12 & 1,11 & 1,11 & 1,07 & 1,07 \\
\hline Tanino (\%) (Tanin) & 0,00 & 0,00 & 0,10 & 0,10 & 0,20 & 0,20 \\
\hline
\end{tabular}

1 Composição por quilograma do produto (Amount per kg of product): Mn, 65.000 mg; Fe, 40.000 mg; Cu, 10.000 mg; Zn, 50.000 mg; I, 1.000 mg.

${ }^{2}$ Composição por quilograma do produto (Amount per kg of product): Vit. A, 2.650.000 UI; Vit. D3, 740.000 UI; Vit. E, 3.650 mg; Vit. K3, 600 mg; Vit. B1, 650 mg; Vit. B2, 1.650 mg; Vit. B6, 1.100 mg; Vit. B12, 4.350 mcg; Pantotenato de cálcio (Calcium panthotenate), 4.000 mg; Niacina (Niacin), 12.000 mg; Ảcido fólico (Folic acid), 270 mg; Selênio (Selenium), 50 mg; Colina (Colin), 170 g; Agente anticoccidiano, 340 g; Promotor de crescimento (Growth promoter), 12 g; Antioxidante (Antioxidant), $34 \mathrm{~g}$.

3 Finnfeeds International. 
Tabela 2 - Composições percentual e calculada das dietas usadas no experimento II (fase final)

Table 2 - Ingredient and calculated compositions of the diets - experiment II (finishing)

\begin{tabular}{|c|c|c|c|c|c|c|}
\hline \multirow[t]{2}{*}{$\begin{array}{l}\text { Ingrediente } \\
\text { Ingredient }\end{array}$} & \multicolumn{6}{|c|}{$\begin{array}{r}\text { Dieta } \\
\text { Diet }\end{array}$} \\
\hline & T 1 & Т 2 & T 3 & $\mathrm{~T} 4$ & T 5 & Т 6 \\
\hline Farelo de soja (Soybean meal) & 32,240 & 32,281 & 32,300 & 32,341 & 29,904 & 29,555 \\
\hline Óleo de soja (Soybean oil) & 4,375 & 4,445 & 4,939 & 5,010 & 4,972 & 4,958 \\
\hline Sorgo granífero (Sorghum) & - & - & 29,913 & 29,913 & 59,826 & 59,826 \\
\hline Calcário calcítico (Limestone) & 1,284 & 1,284 & 1,291 & 1,291 & 1,309 & 1,310 \\
\hline Sal (Salt) & 0,377 & 0,377 & 0,377 & 0,377 & 0,377 & 0,377 \\
\hline Premix mineral ${ }^{1}$ (Mineral premix) & 0,100 & 0,100 & 0,100 & 0,100 & 0,100 & 0,100 \\
\hline Premix vitamínico ${ }^{2}$ (Vitamin premix) & 0,300 & 0,300 & 0,300 & 0,300 & 0,300 & 0,300 \\
\hline DL-metionina (DL-methionine) & 0,176 & 0,176 & 0,193 & 0,193 & 0,190 & 0,187 \\
\hline L-lisina (L-lysine) & 0,003 & 0,002 & 0,018 & 0,017 & 0,091 & 0,100 \\
\hline $\mathrm{EM}(M E), \mathrm{kcal} / \mathrm{kg}$ & 3.200 & 3.200 & 3.200 & 3.200 & 3.200 & 3.200 \\
\hline Proteína bruta (\%) (Crude protein) & 20,00 & 20,00 & 20,00 & 20,00 & 20,00 & 20,00 \\
\hline Fibra bruta (\%) (Crude fiber) & 3,28 & 3,28 & 3,06 & 3,06 & 2,75 & 2,75 \\
\hline Cálcio (\%) (Calcium) & 0,90 & 0,90 & 0,90 & 0,90 & 0,90 & 0,90 \\
\hline Fósforo disponível (\%) (Available P) & 0,35 & 0,35 & 0,35 & 0,35 & 0,35 & 0,35 \\
\hline Metionina (\%) (Methionine) & 0,41 & 0,41 & 0,42 & 0,42 & 0,42 & 0,42 \\
\hline Met + Cis $(\%)($ Met + Cys $)$ & 0,72 & 0,72 & 0,72 & 0,72 & 0,72 & 0,72 \\
\hline Lisina (\%) (Lys) & 1,00 & 1,00 & 1,00 & 1,00 & 1,00 & 1,00 \\
\hline Tanino (\%) (Tanin) & 0,00 & 0,00 & 0,11 & 0,11 & 0,22 & 0,22 \\
\hline
\end{tabular}

Avaliaram-se o consumo de ração, o ganho de peso, a conversão alimentar, o rendimento de carcaça, os pesos relativos de proventrículo, moela, fígado, pâncreas, duodeno, jejuno, íleo e ceco e o grau de pigmentação da perna e analisou-se o sistema econômico de produção.

O consumo de ração foi calculado no $21^{\circ}$ dia do experimento I e no $21 \underline{\mathrm{o}}$ e $42 \underline{\mathrm{o}}$ dia do experimento II, subtraindose da ração fornecida a sobra constante nos comedouros e baldes. O ganho de peso por ave foi determinado pela diferença entre os pesos final e inicial dos experimentos I (1 a 21 dias) e II (21 a 42 dias). A conversão alimentar foi calculada dividindo-se o consumo de ração pelo ganho de peso em cada fase experimental. O rendimento de carcaça (experimento II), em porcentagem do peso vivo, foi estimado pela divisão do peso da carcaça eviscerada pelo peso vivo da ave multiplicado por 100 . A coloração da perna (experimento II) foi determinada pela leitura individual em três aves/boxe, utilizando-se o disco Roche com escala numérica de 0 a 15 . Realizou-se a identificação do número do disco conforme a cor da perna das aves e calculou-se a média de cada boxe.
Os órgãos do trato gastrointestinal foram coletados, lavados, esvaziados e, finalmente, pesados no final dos experimentos I e II. O peso relativo de moela, proventrículo, fígado, pâncreas, duodeno, jejuno, íleo e ceco foi obtido dividindo-se o peso do órgão pelo peso vivo da ave e multiplicando-se o resultado obtido por 100. A análise econômica do custo do quilo de ganho de peso para as diferentes dietas experimentais foi realizada pela multiplicação do custo por quilo de ração pela conversão alimentar, obtendo-se, assim, o custo de ração por quilo de peso vivo produzido, de acordo com Espíndola (1979).

\section{Resultados e Discussão}

A adição do complexo multienzimático ${ }^{1}$ nas rações do experimento I ( 1 a 21 dias) não promoveu alteração significativa no consumo de ração, no ganho de peso e na conversão alimentar dos frangos (Tabela 3 ).

Os parâmetros zootécnicos não foram significativamente influenciados pelo sorgo, como observado também por Bornstein \& Bartov (1967) e Queiroz et al. (1978). Os 
resultados obtidos neste estudo corroboram os encontrados por Costa et al. (1996), que, utilizando ração à base de milho e soja suplementada com carboidrase (Energex) e protease (Biofeed, Alltech), não obtiveram diferenças significativas para essas variáveis.

No experimento II (22 a 42 dias), os parâmetros zootécnicos não foram alterados significativamente pelo uso de sorgo (Tabela 4).

Os resultados desta pesquisa estão de acordo com os dados descritos por Sullivan (1989). O complexo multienzimático reduziu significativamente o rendimento de carcaça, contrariando os dados reportados por de Soto-Salanova et al. (1996), que observaram aumento do músculo de peito em frangos.

A análise de variância do experimento I ( 1 a 21 dias) para os pesos médios de proventrículo, fígado e pâncreas demons- trou não haver diferença significativa na substituição do milho pelo sorgo (Tabela 5), assim como não houve efeito significativo da adição do complexo multienzimático nas rações sobre os pesos relativos de proventrículo, moela, fígado e pâncreas dos frangos.

Neste estudo, o peso médio da moela foi afetado significativamente pelo nível de sorgo, observando-se redução do peso das aves que consumiram dieta com 100\% de sorgo. O resultado da inclusão do sorgo está de acordo com a observação de Vohra et al. (1966), que afirmaram que o tanino interfere no revestimento interno da mucosa, ocasionando degradação do epitélio e, conseqüentemente, menor peso do órgão.

A análise de variância do experimento I (1 a 21 dias) revelou que não houve efeito significativo da substituição do milho pelo sorgo (Tabela 6) sobre os pesos médios de duodeno, jejuno, íleo e ceco.

Tabela 3 - Desempenho de frangos de corte na fase inicial de crescimento ( 1 a 21 dias) alimentados com dietas contendo diferentes níveis de substituição do milho pelo sorgo, suplementadas ou não com complexo multienzimático

Table 3 - Effects of corn replacement with sorghum in the diets supplemented or not with multienzimatic complex on the performance of broiler chicks in the starting phase (1-21 days)

\begin{tabular}{lccc}
\hline $\begin{array}{l}\text { Nível de substituição (\%) } \\
\text { Replacement level }\end{array}$ & $\begin{array}{c}\text { Consumo de ração (g/ave) } \\
\text { Feed intake (g/bird) }\end{array}$ & $\begin{array}{c}\text { Ganho de peso(g/ave) } \\
\text { Weight gain (g/bird) }\end{array}$ & $\begin{array}{c}\text { Conversão alimentar } \\
\text { Feed to gain ratio }\end{array}$ \\
\hline 0 & 997 & 760 & 1,321 \\
50 & 1002 & 765 & 1,321 \\
100 & 1012 & 766 & 1,323 \\
\hline Nível de adição (\%) & & & 1,317 \\
Multienzyme addition & 1000 & 761 & 1,321 \\
$0 \quad$ Enz & 1008 & 766 & 2,41 \\
0,1 Enz & 4,01 & 3,48 & \\
CV (\%) & & & \\
\hline
\end{tabular}

Não-significativo $(P>0,05)$

Not significant differences $(P>0.05)$.

Tabela 4 - Desempenho de frangos de corte na fase final de crescimento ( 21 a 42 dias) alimentados com dietas contendo diferentes níveis de substituição do milho pelo sorgo, suplementadas ou não com complexo multienzimático

Table 4 - Effects of corn replacement with sorghum in the diets supplemented or not with multienzimatic complex on the performance of broiler chicks in the finishing phase(21-42 days)

\begin{tabular}{lcccc}
$\begin{array}{l}\text { Nível de substituição (\%) } \\
\text { Replacement level }\end{array}$ & $\begin{array}{c}\text { Consumo de ração } \\
\text { (g/ave) } \\
\text { Feed intake (g/bird) }\end{array}$ & $\begin{array}{c}\text { Ganho de peso } \\
\text { (g/ave) } \\
\text { Weight gain (g/bird) }\end{array}$ & $\begin{array}{c}\text { Conversão alimentar } \\
\text { Feed to gain ratio }\end{array}$ & $\begin{array}{c}\text { Rendimento } \\
(\% \text { peso vivo) } \\
\text { Carcass yield }\end{array}$ \\
\hline 0 & 2891 & 1434 & 2,021 & 72,15 \\
50 & 2900 & 1439 & 1,971 & 71,46 \\
100 & 2899 & 1397 & 2,082 & 71,59
\end{tabular}

Nível de adição (\%)

Multienzyme addition

\begin{tabular}{lcccc}
\hline $0 \quad$ Enz & $2897^{\mathrm{a}}$ & $1436^{\mathrm{a}}$ & $2,033^{\mathrm{a}}$ & $72,19^{\mathrm{a}}$ \\
0,1 Enz & $2897^{\mathrm{a}}$ & $1407^{\mathrm{a}}$ & $2,016^{\mathrm{a}}$ & $71,28^{\mathrm{b}}$ \\
$\mathrm{C}$ V $(\%)$ & 6,30 & 4,30 & 8,92 & 2,00
\end{tabular}

Médias seguidas de mesma letra, na coluna, não diferem $(P>0,05)$ pelo teste Tukey.

Means followed by the same letters, within a columm, do not differ $(P>0.05)$ by Tukey test. 
Tabela 5 - Peso relativo de órgãos do trato gastrointestinal de frangos de corte na fase inicial de crescimento (1 a 21 dias) alimentados com dietas contendo diferentes níveis de substituição do milho pelo sorgo, suplementadas ou não com complexo multienzimático

Table 5 - Effects corn replacement with sorghum in the diets supplemented or not with multienzimatic complex on the relative weights of sections of the gastrointestinal tract of broiler chicks in the starter phase (1-21 days)

\begin{tabular}{|c|c|c|c|c|}
\hline $\begin{array}{l}\text { Nível de substituição (\%) } \\
\text { Replacement }\end{array}$ & $\begin{array}{c}\text { Proventrículo }(\mathrm{g} / 100 \mathrm{~g}) \\
\text { Proventriculus }\end{array}$ & $\begin{array}{c}\text { Moela }(\mathrm{g} / 100 \mathrm{~g}) \\
\text { Gizzard }\end{array}$ & $\begin{array}{c}\text { Fígado }(\mathrm{g} / 100 \mathrm{~g}) \\
\text { Liver }\end{array}$ & $\begin{array}{c}\text { Pâncreas }(\mathrm{g} / 100 \mathrm{~g}) \\
\text { Pancreas }\end{array}$ \\
\hline 0 & $0,57^{\mathrm{a}}$ & $2,66^{\mathrm{a}}$ & $2,64^{\mathrm{a}}$ & $0,31^{\mathrm{a}}$ \\
\hline 50 & $0,56^{\mathrm{a}}$ & $2,59^{\mathrm{ab}}$ & $2,63^{\mathrm{a}}$ & $0,31^{\mathrm{a}}$ \\
\hline 100 & $0,56^{\mathrm{a}}$ & $2,38^{\mathrm{b}}$ & $2,72^{\mathrm{a}}$ & $0,28^{\mathrm{a}}$ \\
\hline \multicolumn{5}{|l|}{$\begin{array}{l}\text { Nível de adição (\%) } \\
\text { Multienzyme addition }\end{array}$} \\
\hline \multicolumn{5}{|l|}{ Multienzyme addition } \\
\hline $0 \quad$ Enz & 0,56 & 2,60 & 2,73 & 0,30 \\
\hline $0,1 \mathrm{Enz}$ & 0,57 & 2,49 & 2,60 & 0,29 \\
\hline CV (\%) & 11,45 & 10,49 & 13,03 & 17,85 \\
\hline
\end{tabular}

Médias seguidas de mesma letra, na coluna, não diferem $(P>0,05)$ pelo teste Tukey.

Means followed by the same letters, within a columm, do not differ $(P>0.05)$ by Tukey test.

Tabela 6 - Peso relativo das partes dos intestinos de frangos de corte na fase inicial de crescimento ( 1 a 21 dias) alimentados com dietas contendo diferentes níveis de substituição do milho pelo sorgo, suplementadas ou não com complexo multienzimático

Table 6 - Effects of corn replacement with sorghum in the diets supplemented or not with multienzimatic complex on the relative weights of sections of intestine of broiler chicks in the starter phase (1-21 days)

\begin{tabular}{|c|c|c|c|c|}
\hline $\begin{array}{l}\text { Nível de substituição (\%) } \\
\text { Replacement level }\end{array}$ & $\begin{array}{c}\text { Duodeno }(\mathrm{g} / 100 \mathrm{~g}) \\
\text { Duodenum }\end{array}$ & $\begin{array}{c}\text { Jejuno }(\mathrm{g} / 100 \mathrm{~g}) \\
\text { Jejunum }\end{array}$ & $\begin{array}{l}\text { Íleo }(\mathrm{g} / 100 \mathrm{~g}) \\
\text { Ileum }\end{array}$ & $\begin{array}{c}\text { Cecos }(\mathrm{g} / 100 \mathrm{~g}) \\
\text { Ceсum }\end{array}$ \\
\hline 0 & 0,97 & 1,37 & 1,09 & 0,42 \\
\hline 50 & 0,93 & 1,42 & 1,06 & 0,49 \\
\hline 100 & 0,95 & 1,38 & 1,16 & 0,50 \\
\hline
\end{tabular}

Nível de adição (\%)

Multienzyme addition

\begin{tabular}{|c|c|c|c|c|}
\hline $0 \quad$ Enz & $0,93^{\mathrm{a}}$ & $1,31^{b}$ & $1,05^{b}$ & $0,47^{\mathrm{a}}$ \\
\hline $0,1 \mathrm{Enz}$ & $0,97^{\mathrm{a}}$ & $1,47^{\mathrm{a}}$ & $1,15^{\mathrm{a}}$ & $0,48^{\mathrm{a}}$ \\
\hline CV (\%) & 18,5 & 15,31 & 11,13 & 20,32 \\
\hline
\end{tabular}

Médias seguidas de mesma letra, na coluna, não diferem $(P>0,05)$ pelo teste Tukey.

Means followed by the same letters, within a columm, do not differ $(P>0.05)$ by Tukey test.

Os resultados deste estudo revelaram que a adição do complexo multienzimático ocasionou aumento significativo no peso do jejuno e íleo dos frangos. Os resultados encontrados no experimento I ( 1 a 21 dias) para os pesos relativos do jejuno e íleo, com complexo enzimático adicionado à ração, estão de acordo com os relatados por Ritz et al. (1995). Esses pesquisadores, trabalhando com dietas à base de milho+soja, suplementada com amilase ou xilanase, observaram, em perus, aumento significativo do comprimento médio das vilosidades do jejuno e íleo em dietas com amilase. Estes dados sugerem que o aumento das vilosidades proporcionou acréscimo no peso do duodeno e jejuno.

O peso relativo do proventrículo, da moela, do fígado e do pâncreas do experimento II ( 22 a 42 dias) não foi significativamente influenciado pela quantidade de sorgo na ração (Tabela 7).

A adição do complexo multienzimático ocasionou aumento significativo dos pesos do proventrículo, da moela e do pâncreas. Os valores encontrados divergem dos relatados por Brenes (1993), que, adicionando xilanase em dieta à base de cevada, reduziu o peso relativo do proventrículo, do pâncreas e do fígado.
O peso relativo de duodeno, jejuno, íleo e ceco do experimento II ( 22 a 42 dias) não foram significativamente influenciados pelo nível de substituição do milho pelo sorgo e pelo nível de adição do complexo enzimático (Tabela 8).

Os resultados obtidos neste estudo contrariam os relatados por Brenes (1993), que, adicionando xilanase em dietas com cevada, observou redução do peso relativo de duodeno, jejuno, íleo e ceco.

A análise de variância do experimento II (22 a 42 dias) para a pigmentação da perna demonstrou redução significativa na pigmentação quando o milho foi substituído pelo sorgo (Tabela 9).

Os valores registrados coincidem com os reportados por Bonrstein \& Bartov (1967) e Sulivan (1989), que analisaram os níveis de inclusão do sorgo em substituição ao milho em rações para frangos de corte e encontraram diferenças significativas na pigmentação da perna de frangos de corte.

Neste ensaio, a adição do complexo multienzimático na ração não alterou significativamente a pigmentação da perna dos frangos. Entretanto, Furlan et al. (1997), trabalhando com dieta à base de triticale-soja, observaram melhor 
Tabela 7 - Peso relativo dos órgãos do trato gastrointestinal de frangos de corte na fase final de crescimento ( 21 a 42 dias) alimentados com dietas contendo diferentes níveis de substituição do milho pelo sorgo, suplementadas ou não com complexo multienzimático

Table 7 - Effects corn replacement with sorghum in the diets supplemented or not with multienzimatic complex on the relative weights of gastrointestinal tract of broiler chicks in the finishing phase (21-42 days)

\begin{tabular}{|c|c|c|c|c|}
\hline $\begin{array}{l}\text { Nível de substituição (\%) } \\
\text { Replacement }\end{array}$ & $\begin{array}{c}\text { Proventrículo }(\mathrm{g} / 100 \mathrm{~g}) \\
\text { Proventriculus }\end{array}$ & $\begin{array}{c}\text { Moela }(\mathrm{g} / 100 \mathrm{~g}) \\
\text { Gizzard }\end{array}$ & $\begin{array}{c}\text { Fígado }(\mathrm{g} / 100 \mathrm{~g}) \\
\text { Liver }\end{array}$ & $\begin{array}{c}\text { Pâncreas }(\mathrm{g} / 100 \mathrm{~g}) \\
\text { Pancreas }\end{array}$ \\
\hline 0 & 0,38 & 2,16 & 1,85 & 0,21 \\
\hline 50 & 0,40 & 2,18 & 1,97 & 0,22 \\
\hline 100 & 0,41 & 1,94 & 1,85 & 0,21 \\
\hline \multicolumn{5}{|l|}{$\begin{array}{l}\text { Nível de adição (\%) } \\
\text { Multienzyme addition }\end{array}$} \\
\hline $0 \quad$ Enz & $0,37^{b}$ & $1,97^{\mathrm{b}}$ & $1,87^{\mathrm{a}}$ & $0,20^{\mathrm{b}}$ \\
\hline 0,1 Enz & $0,42^{\mathrm{a}}$ & $2,22^{\mathrm{a}}$ & $1,91^{\mathrm{a}}$ & $0,23^{\mathrm{a}}$ \\
\hline CV (\%) & 21,7 & 14,82 & 13,45 & 17,09 \\
\hline
\end{tabular}

Médias seguidas de mesma letra, na coluna, não diferem $(P>0,05)$ pelo teste Tukey.

Means followed by the same letters, within a columm, do not differ $(P>0.05)$ by Tukey test.

Tabela 8 - Peso relativo das partes dos intestinos de frangos de corte na fase final de crescimento (21 a 42 dias) alimentados com dietas contendo diferentes níveis de substituição do milho pelo sorgo, suplementadas ou não com complexo multienzimático

Table 8 - Effects of corn replacement with sorghum in the diets supplemented or not with multienzimatic complex on the relative weights of sections of intestine of broiler chicks in the finishing phase (21-42 days)

\begin{tabular}{|c|c|c|c|c|}
\hline $\begin{array}{l}\text { Nível de substituição (\%) } \\
\text { Replacement level }\end{array}$ & $\begin{array}{c}\text { Duodeno }(\mathrm{g} / 100 \mathrm{~g}) \\
\text { Duodenum }\end{array}$ & $\begin{array}{c}\text { Jejuno }(\mathrm{g} / 100 \mathrm{~g}) \\
\text { Jejuпит }\end{array}$ & $\begin{array}{l}\text { Íleo }(\mathrm{g} / 100 \mathrm{~g}) \\
\text { Ileum }\end{array}$ & $\begin{array}{c}\text { Cecos }(\mathrm{g} / 100 \mathrm{~g}) \\
\text { Ceсum }\end{array}$ \\
\hline 0 & 0,60 & 0,89 & 0,72 & 0,39 \\
\hline 50 & 0,59 & 0,86 & 0,73 & 0,36 \\
\hline 100 & 0,64 & 0,86 & 0,73 & 0,38 \\
\hline \multicolumn{5}{|l|}{$\begin{array}{l}\text { Nível de adição (\%) } \\
\text { Multienzyme addition }\end{array}$} \\
\hline $0 \quad$ Enz & 0,59 & 0,87 & 0,72 & 0,38 \\
\hline $0,1 \mathrm{Enz}$ & 0,63 & 0,87 & 0,74 & 0,37 \\
\hline CV (\%) & 22,01 & 17,86 & 15,56 & 15,57 \\
\hline
\end{tabular}

Não-significativo $(P>0,05)$.

Not significant $(P>0.05)$.

Tabela 9 - Grau de pigmentação da perna de frangos de corte na fase final de crescimento ( 21 a 42 dias) alimentados com dietas contendo diferentes níveis de substituição do milho pelo sorgo, suplementadas ou não com complexo multienzimático

Table 9 - Effects corn replacement with sorghum in the diets supplemented or not with multienzimatic complex, on the shanks pigmentation of broiler chicks, at finishing phase (21-42 days)

\begin{tabular}{lc}
\hline $\begin{array}{l}\text { Nível de substituição (\%) } \\
\text { Replacement level }\end{array}$ & Média (score 0 a 15) \\
\hline 0 & Mean \\
50 & $3,42^{\mathrm{a}}$ \\
100 & $2,34^{\mathrm{b}}$ \\
\hline
\end{tabular}

Nível de adição (\%)

Multienzyme addition

\begin{tabular}{llc}
\hline 0 & Enz & 2,44 \\
0,1 & Enz & 2,46 \\
CV $(\%)$ & 26,86 \\
\hline
\end{tabular}

Médias seguidas de mesma letra, na coluna, não diferem $(P>0,05)$ pelo teste Tukey.

Means followed by the same letters, within a columm, do not differ $(P>0.05)$ by Tukey test. pigmentação da pele das aves quando as rações foram suplementadas com pentosanase, celulase e hemicelulase.

A análise econômica da pesquisa revelou variação no custo por quilo de peso vivo produzido entre os tratamentos adotados nos dois experimentos (Tabela 10).

Neste estudo, foi constatado que a melhor conversão alimentar- e, conseqüentemente, o menor custo de produção - ocorreu nas aves alimentadas com as dietas inicial e final com $50 \%$ de sorgo, sem adição do complexo multienzimático.

\section{Conclusões}

A substituição do milho pelo sorgo nos níveis de 0,50 e $100 \%$ em rações para frangos de corte não alterou significativamente o consumo de ração, o ganho de peso, a conversão alimentar e os pesos relativos do proventrículo, do pâncreas e do fígado. Houve alteração significativa no 
Tabela 10 - Custo de $1 \mathrm{~kg}$ de ganho de peso de frango de corte, em função da conversão alimentar média e do custo de cada dieta, nas fases inicial (experimento I) e final (experimento II)

Table 10 - Cost of $1 \mathrm{~kg}$ of body weight gain broiler chicks, according to average feed:gain ratio and individual diet cost in the starter (experiment I) and finishing phases (experiment II)

\begin{tabular}{|c|c|c|c|c|c|c|}
\hline \multirow[t]{2}{*}{$\begin{array}{l}\text { Tratamento } \\
\text { Treatment }\end{array}$} & \multicolumn{3}{|c|}{$\begin{array}{l}\text { Experimento I (fase inicial: } 1-21 \text { dias) } \\
\text { Experiment I (starter phase: } 1-21 \text { days) }\end{array}$} & \multicolumn{3}{|c|}{$\begin{array}{l}\text { Experimento II (fase final: } 22-42 \text { dias) } \\
\text { Experiment II (finishing phase: } 22-42 \text { days) }\end{array}$} \\
\hline & $\begin{array}{c}\text { Custo } / \mathrm{kg} \\
\text { ração }(\mathrm{R} \$) \\
\text { Cost/kg feed }(R \$)\end{array}$ & $\begin{array}{c}\text { Conversão } \\
\text { alimentar } \\
\text { Feed:gain ratio }\end{array}$ & $\begin{array}{c}\text { Custo/kg peso vivo } \\
\text { produzido (R\$) } \\
\text { Cost/kg body } \\
\text { weight }(R \$)\end{array}$ & $\begin{array}{c}\text { Custo } / \mathrm{kg} \\
\text { ração }(\mathrm{R} \$) \\
\text { Cost/kg diet }(R \$)\end{array}$ & $\begin{array}{c}\text { Conversão } \\
\text { alimentar } \\
\text { Feed conversion }\end{array}$ & $\begin{array}{c}\text { Custo } / \mathrm{kg} \text { peso } \\
\text { vivo produzido (R\$) } \\
\text { Cost } / \mathrm{kg} \text { body } \\
\text { weight }(R \$)\end{array}$ \\
\hline Sorgo - 0Enz - 0 & & & & & & \\
\hline $\begin{array}{l}\text { Sorghum - OEnzyme }-0.1 \% \\
\text { Sorgo }-50 \% \text { Enz }-0\end{array}$ & 0,27 & 1,31 & 0,36 & 0,27 & 2,02 & 0,54 \\
\hline Sorghum - 50\%Enzyme - 0 & 0,27 & 1,31 & 0,36 & 0,26 & 2,02 & 0,53 \\
\hline $\begin{array}{l}\text { Sorgo - } 50 \% \text { Enz }-0,1 \% \\
\text { Sorghum }-50 \% \text { Enzyme - } 0.1 \%\end{array}$ & 0,28 & 1,33 & 0,37 & 0,27 & 2,05 & 0,55 \\
\hline $\begin{array}{l}\text { Sorgo }-100 \% \text { Enz - } 0 \\
\text { Sorghum }-100 \% \text { Enzyme - } 0\end{array}$ & 0,27 & 1,32 & 0,36 & 0,27 & 2,06 & 0,55 \\
\hline
\end{tabular}

grau de pigmentação das aves com a substituição do milho pelo sorgo, constatando-se redução na pigmentação à medida que se aumentou o nível de sorgo na dieta.

A adição do complexo multienzimático em rações para frangos de corte promoveu aumento significativo no peso relativo do jejuno, do íleo, do proventrículo, da moela e do pâncreas, entretanto reduziu significativamente o rendimento de carcaça.

O sorgo pode substituir o milho em até $50 \%$ em dietas para frangos de corte nas fases inicial e final de crescimento. O uso do complexo multienzimático aumentou o custo do quilo de carne produzido.

\section{Literatura Citada}

BEDFORD, M.R. Efecto del uso de enzimas digestivas en la alimentación de aves. Avicultura Profesional, v.14, n.4, p.24-29, 1996.

BONRSTEIN, S; BARTOV, I. Comparisons of sorghum and maize as the principal cereal grain source in poultry rations. Poultry Science, v.8, p.213-221, 1967.

BRENES, A.; SMITH, M.; GUENTER, W.E. et al. Effect of enzyme supplementation on the performance and disgetive tract size of broiler chickens fed wheat and barley based diets. Poultry Science, v.72, p.1731-1739, 1993.

COSTA, F.G.P.; BRANDÃO, J.S.; ALCÂNTARA, M.A. Efeito de diferentes níveis de enzimas na ração inicial sobre o desempenho de frangos de corte. In: REUNIÃO ANUAL DA SOCIEDADE BRASILEIRA DE ZOOTECNIA, 33., 1996, Fortaleza. Anais... Fortaleza: Sociedade Brasileira de Zootecnia, 1996. p.71-76.

ESPÍNDOLA, G.B. Substituição da farinha de peixe por subprodutos da indústria avícola na alimentação de frangos de corte. Santa Maria: Universidade Federal de Santa Maria, 1979. 72p. Dissertação (Mestrado em Zootecnia) - Universidade Federal de Santa Maria, 1979.

FURLAN, A.C.; FRAIHA, M.; MURAKAMI, A.E. Utilização de complexo multienzimático em dietas de frangos de corte contendo triticale. 2. Ensaio de desempenho. Revista da Sociedade Brasileira de Zootecnia, v.26, n.4, p.765-772, 1997.

GUALTIERI, M.; RAPACCINI, S. Sorghum grain in poultry feeding. World's Poultry Science Journal, v.46, p.246-254, 1990. NATIONAL RESEARCH COUNCIL - NRC. Nutrient requirements of poultry. Washington, D.C.: National Academy Press, 1994. $155 \mathrm{p}$.

QUEIROZ, A.C.; ROSTAGNO, H.S.; FONSECA, J.H. et al. Sorgos com diferentes conteúdos de tanino como substitutos do milho para aves. Revista Ceres, v.25, n.139, p.234-241, 1978.

RITZ, C.W.; HULET, R.M.; SELF, B.B. et al. Growth and intestinal morphology of male turkeys as influenced by dietary supplementation of amylase and xylanase. Poultry Science, v.74, p.1329-1334, 1995.

STATISTICAL ANALYSES SYSTEM - SAS. SAS User's guide statistics. Version 6. 12.ed. Cary: 1996.

SOTO-SALANOVA, M.F.; GARCIA, O.; GRAHAM, H. et al. Uso de enzimas em dietas de milho e soja para frangos de corte. In: CONFERENCIA APINCO DE CIÊNCIA E TECNOLOGIA AVÍCOLAS, Curitiba, 1996. Trabalhos de Pesquisa... Associação Brasileira de Produtores de Pintos de Corte, 1996. p.71-76.

SOTO-SALANOVA, M.F.; WYATT, C.L. Uso de enzimas para alcanzar el máximo potencial de las materias-primas para dietas de avicultura. Minneapolis: Midwest Poultry Federation Convention, 1997 (CD-ROM).

SULLIVAN, T. Grano de sorgo: alternativa del maíz. Indústria Avícola, n.10, p.10-15, 1989.

VOHRA, P.; KRATER, F.H.; JOSLYN, M.A. The growth depressing and toxic effects of tannins to chicks. Poultry Science, v.45, p.135-142, 1966 . 